\title{
Type I enteropathy-associated T-cell lymphoma in the colon of a 29-year-old patient and a brief literature review
}

This article was published in the following Dove Press journal:

OncoTargets and Therapy

22 February 2016

Number of times this article has been viewed

\author{
Jiu-Cong Zhang \\ Yong Wang \\ Xiu-Feng Wang \\ Fang-Xin Zhang
}

Department of Gastroenterology, Lanzhou General Hospital of Lanzhou Military Command, Lanzhou, People's Republic of China
Correspondence: Fang-Xin Zhang Department of Gastroenterology, Lanzhou General Hospital of Lanzhou Military Command, 333rd Binhenan Road, Qilihe District, Lanzhou 730050, People's Republic of China

$\mathrm{Tel}+869318995131$

Email zhangjiucong@।63.com

\begin{abstract}
Enteropathy-associated T-cell lymphoma (EATL) is a rare gastrointestinal non-Hodgkin's lymphoma, originating from intraepithelial T-lymphocyte, which is specifically associated with celiac disease. EATL most commonly presents in the sixth and seventh decades of life. We report a unique case of type I EATL in the colon with liver metastasis, which was presented with nonspecific radiological findings and at a very young age ( 29 years old) compared with previously published data. We suggest that EATL should be regarded as part of differential diagnosis in any patient presenting with abdominal pain, diarrhea, weight loss, and malabsorption because delay in treatment can result in an irreversible clinical outcome.
\end{abstract}

Keywords: enteropathy-associated T-cell lymphoma, colon, ulcer, liver metastasis

\section{Introduction}

Celiac disease (CD) is an autoimmune disorder of the small intestine. ${ }^{1}$ Enteropathy-associated T-cell lymphoma (EATL) is a rare gastrointestinal non-Hodgkin's lymphoma, originating from intraepithelial T-lymphocyte, which is specifically associated with CD. ${ }^{2}$ Based on the morphology, immunohistochemistry, and genetic profile, EATL can be divided into two groups. EATL type I is associated with refractory $\mathrm{CD}$ and comprises $80 \%-90 \%$ of all cases. EATL type II is sporadic, with no known association with CD, and comprises $10 \%-20 \%$ of all cases. The annual incidence of EATL is $0.5-1$ per million people per year in Western countries. EATL most commonly presents in the sixth and seventh decades of life. Men and women appear to be equally affected. ${ }^{3}$

The disease was difficult to diagnose because it often presented with nonspecific clinical manifestations such as abdominal pain and fever and the endoscopic performance was also difficult to distinguish from intestinal tuberculosis, Crohn's disease, intestinal Behcet's disease, and colon cancers. ${ }^{4}$ Although histopathological examination is the gold standard for its diagnosis, in most cases, mucosal biopsy of highly malignant lesions could find only the infiltration of inflammatory cells. ${ }^{5}$ These reasons lead to high rates of misdiagnosis. We recently treated a patient with EATL at a very young age. Herein, we intend to introduce this case to improve the understanding of the disease and to avoid the clinical misdiagnosis.

\section{Case presentation}

A previously healthy 29-year-old Chinese man with no medical history reported to the practice after 2 weeks of yellowish staining of sclera, skin, and urine and 6 months of abdominal pain, diarrhea, intermittent hematochezia, and $20 \mathrm{~kg}$ weight loss. He was 
a local farmer. He had a 7-year smoking history with nearly 20 cigarettes per day. There were no similar symptoms, no infectious diseases, and no evident hereditary diseases in his family history, and no clear cut history of malabsorption was obtained. He was hospitalized and diagnosed with Crohn's disease as colonoscopy revealed multiple mucosal ulcers in the colon and biopsy demonstrated noncaseating necrotic granuloma in the ileocecal junction mucosa. He was given mesalazine for 2 months without benefit. As the patient was observed to be febrile at $39.6^{\circ} \mathrm{C}$ for 4 days, he was transferred to our facility. Physical examination showed a temperature of $38.5^{\circ} \mathrm{C}$, and he was tachycardic, and cachectic. There was a suspected shifting dullness and tenderness in the right lower quadrant of the abdomen with no further abnormalities, including the absence of palpable lymph nodes.

Initial laboratory investigation revealed raised inflammatory markers: white blood cell count $2.77 \times 10^{9} / \mathrm{L}, \mathrm{C}$-reactive protein $3.4 \mathrm{mg} / \mathrm{dL}$; severe anemia: hemoglobin $45 \mathrm{~g} / \mathrm{L}$, red blood cell count $2.42 \times 10^{12} / \mathrm{L}$; liver dysfunction: alanine aminotransferase $157 \mathrm{IU} / \mathrm{L}$, aspartate aminotransferase $425 \mathrm{IU} / \mathrm{L}$, total bilirubin $174 \mu \mathrm{mol} / \mathrm{L}$, direct bilirubin $158.8 \mu \mathrm{mol} / \mathrm{L}$, albumin $25.4 \mathrm{~g} / \mathrm{L}$, alkaline phosphatase $289 \mathrm{IU} / \mathrm{L}$, gammaglutamyl transpeptidase $166 \mathrm{IU} / \mathrm{L}$, activated partial thromboplastin time 41.1 seconds, prothrombin time $\% 68.9 \%$; and electrolyte disturbances: $\mathrm{K}^{+} 3.1 \mathrm{mmol} / \mathrm{L}, \mathrm{Na}^{+} 128.5 \mathrm{mmol} / \mathrm{L}$, $\mathrm{Cl}^{-} 94.1 \mathrm{mmol} / \mathrm{L}$. Stool examination revealed occult blood; repeat hemocultures and stool cultures were negative; autoantibodies, tuberculin test, serum alpha fetoprotein and carcinoma embryonic antigen were unrevealing. The patient was also negative for human immunodeficiency virus, cytomegalovirus, and hepatic virus infection.

Abdominal ultrasound revealed seroperitoneum, enlargement of the liver and spleen, and chronic cholecystitis.

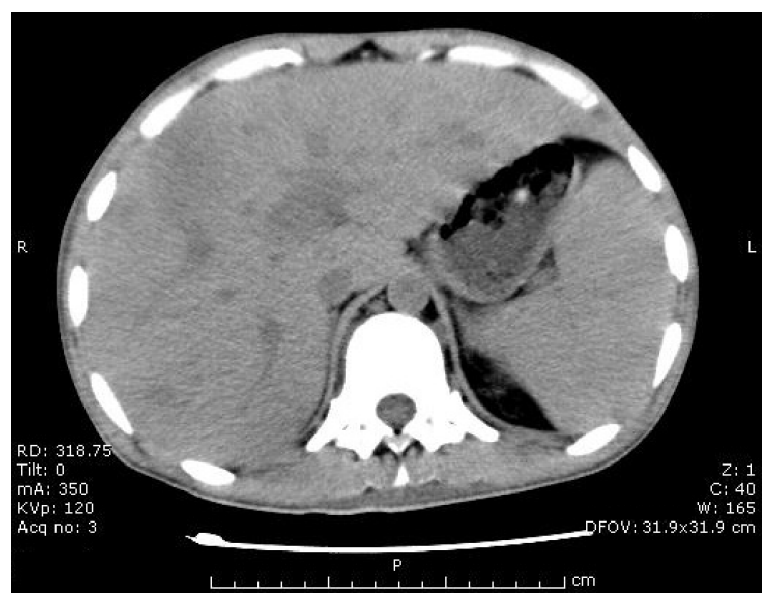

Figure I Abdominopelvic computed tomography. Abbreviations: $R$, right; L, left.

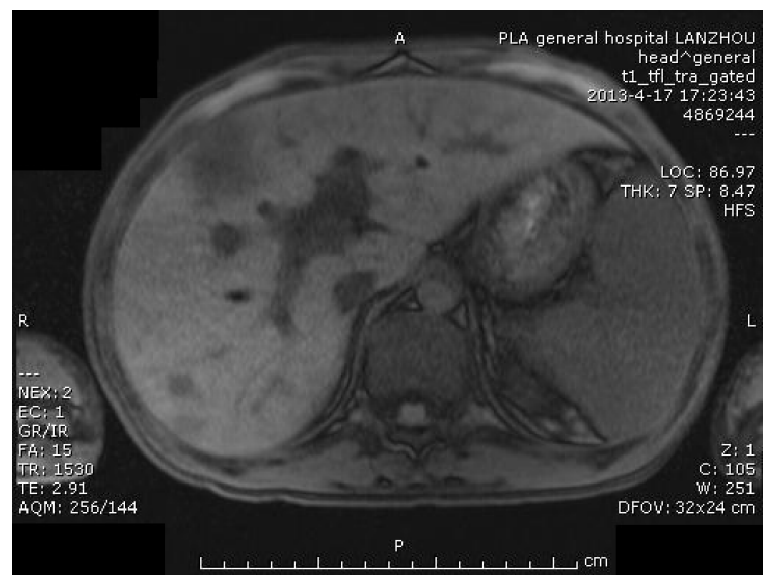

Figure 2 Abdominal magnetic resonance imaging (cross section). Abbreviations: $R$, right; L, left.

Abdominal computed tomography (CT) (Figure 1) scan showed altered liver shape with multiple low-density shadow, considering abscess combining with enhancement CT; several swelling lymph nodes in the intra-abdominal and retroperitoneal, considering reactive hyperplasia; seroperitoneum; cholecystitis; bilateral pleural thickening and bilateral pleural effusion; and reduced heart density, considering anemia. Whole abdominal magnetic resonance imaging (Figures 2 and 3) showed abnormal shape and size of liver, multiple

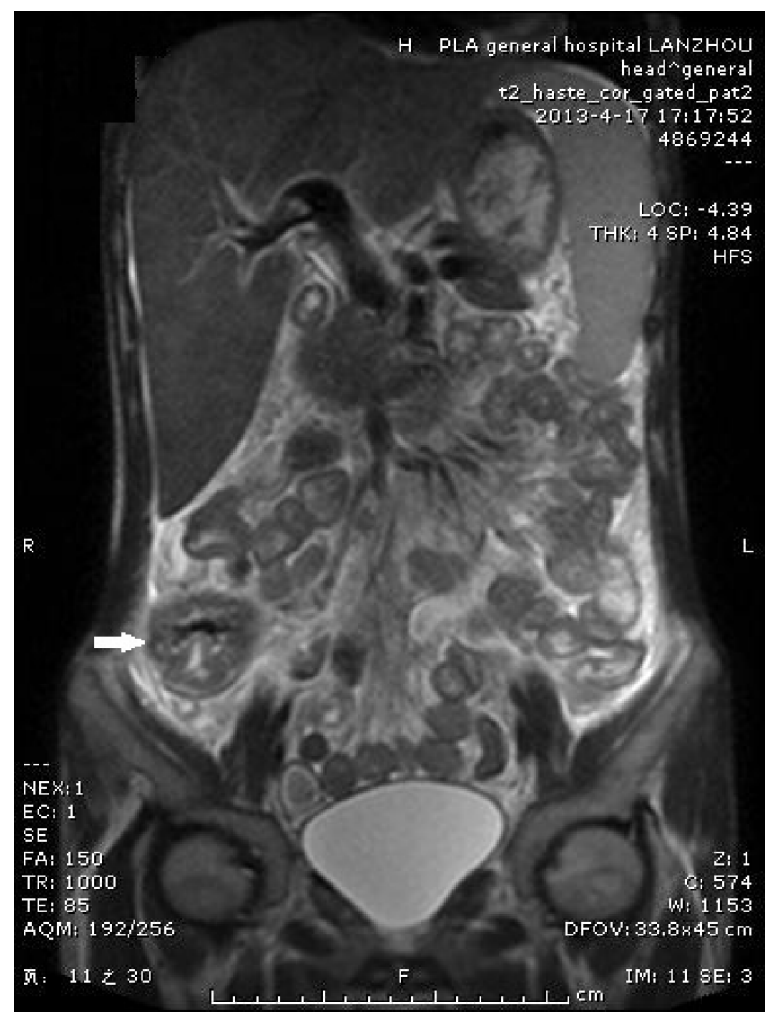

Figure 3 Abdominal magnetic resonance imaging (coronal plane).

Note: The arrow indicates morphological abnormality and signal disorder in ileocecal intestinal canal from abdominal magnetic resonance imaging. Abbreviations: $R$, right; L, left. 
abnormal signals in liver parenchyma, considering abscess; several swelling lymph nodes in the intra-abdominal and retroperitoneal, considering reactive hyperplasia; morphological abnormality and signal disorder in ileocecal intestinal canal, considering inflammatory bowel disease combining with previous history; cholecystitis; hydrothorax; seroperitoneum; and pelvic effusion. The initial diagnosis was Crohn's disease, fever of unknown (intra-abdominal abscess suspected), anemia, hypoproteinemia, electrolyte disturbances (hyponatremia, hypokalemia, hypochloremia), and cholecystitis. Therefore, mesalazine was given for the diagnosis of Crohn's disease, levofloxacin lactate was used for anti-infection, compounds glycyrrhizin and reduced glutathione were used for hepatoprotection, other treatment including hemostatic therapy, blood transfusion, and nutritional support.

On day 4 of his admission, the patient again had fever (the highest temperature was $40^{\circ} \mathrm{C}$ ) and diarrhea (yellow liquid stools for more than ten times), so levofloxacin lactate was replaced by cefoperazone sodium and sulbactam sodium with ornidazole. On day 8 of his admission, the patient presented frequent hematochezia with fever (the highest temperature was $39^{\circ} \mathrm{C}$ ); methylprednisolone and hemostatics were administered. On day 9 of his admission, hemorrhagic shock occurred by massive lower gastrointestinal hemorrhage with heart rate 130 counts per minute and blood pressure $85 / 50 \mathrm{mmHg}$. The total blood loss in day 8 and day 9 was nearly $1,800 \mathrm{~mL}$; emergent colonoscopy at bedside was performed, which showed colon crispation, mass hematocele, and multiple inequivalence deep mucosal ulcers; the terminal ileum mucosa was edematous mucosa with a mosaic pattern, while the ileocecal valve was in an open state with deformities (Figure 4A); an ulcerated mass was also observed in ascending colon near the ileocecal junction (Figure 4B); multiple discrete or punched-out ulcerative
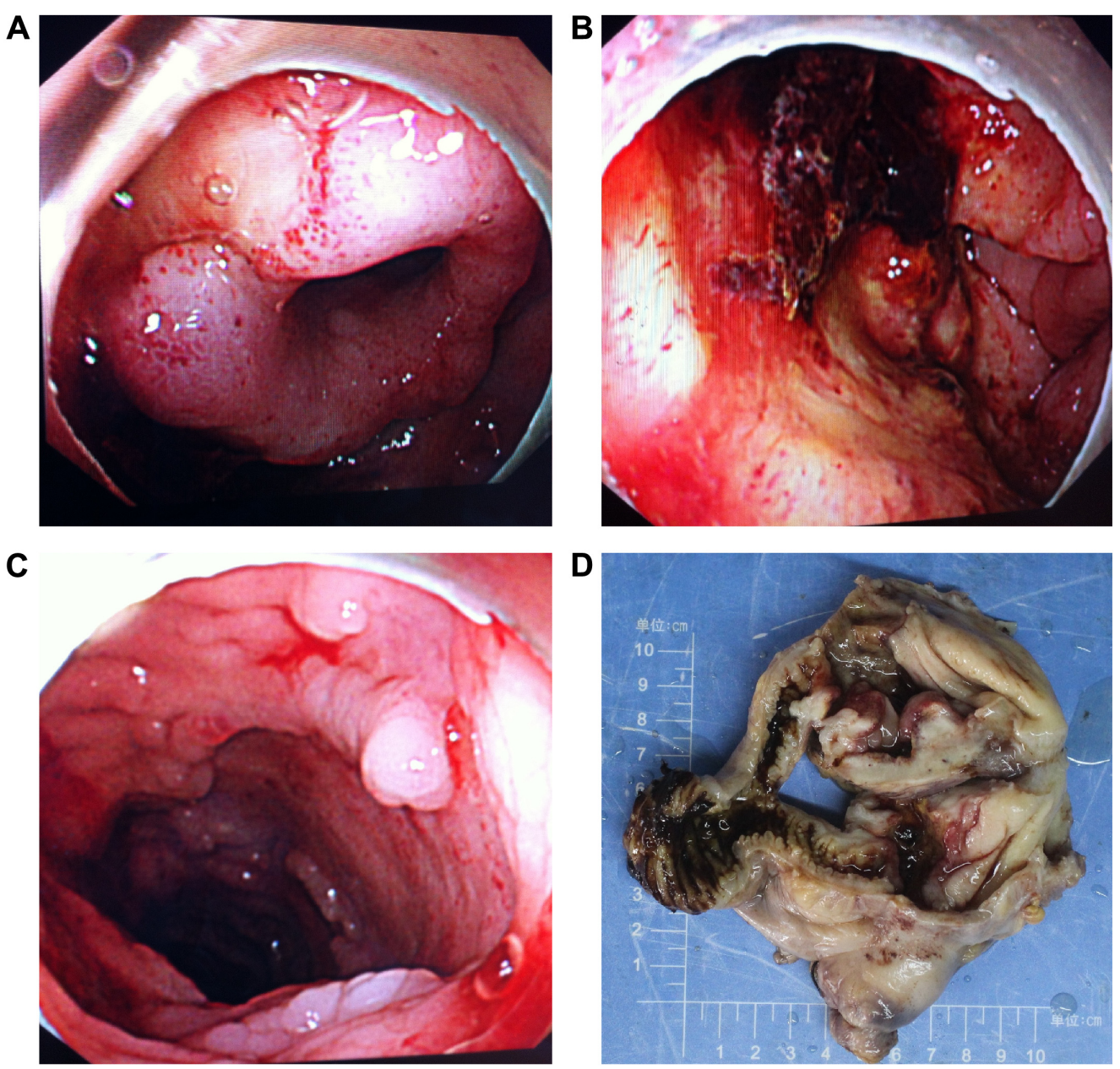

Figure 4 Endoscopic findings and gross appearance of the ulcerated mass.

Notes: (A) Colonoscopy revealed that the terminal ileum mucosa is edematous mucosa with a mosaic pattern and the ileocecal valve is in an open state with deformities. (B) Colonoscopy revealed that an ulcerated mass was also observed in the ascending colon near the ileocecal junction. (C) Colonoscopy revealed that multiple discrete or punched-out ulcerative lesions can be seen in the thickened mucosa in the rest of colon. (D) A gross specimen was obtained from the ileocecal junction after right hemicolectomy. There is an ulcero-infiltrative mass measuring $6 \mathrm{~cm} \times 6 \mathrm{~cm} \times 2 \mathrm{~cm}$. There is also a $3 \mathrm{~cm} \times 2 \mathrm{~cm} \times 2 \mathrm{~cm}$ gray white nodule that appears to extend to serosa. 

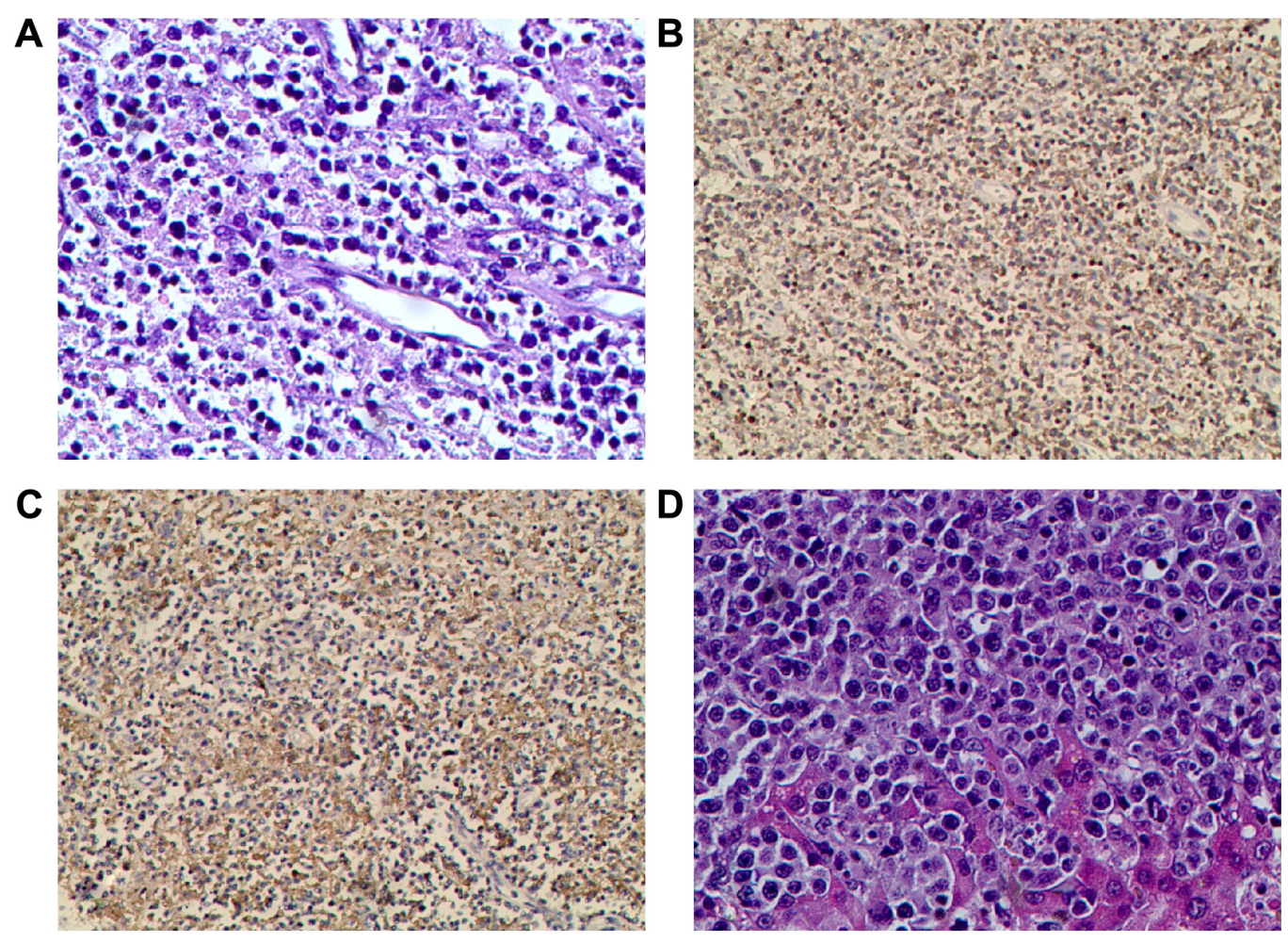

Figure 5 Histological findings of the ulcerated mass and liver biopsy.

Notes: (A) Hematoxylin and eosin staining of the specimens obtained by hemicolectomy showed infiltration of monomorphic and small- to medium-sized lymphoma cells in the mucosa and submucosa $(\times 400)$. (B) Immunohistochemical staining revealed strong expression of CD3 by diffusely distributed atypical lymphocytes, confirming T-lymphocyte origin $(\times 200)$. (C) Immunohistochemistry demonstrating diffuse strong positivity for CD30 was also observed $(\times 200)$. (D) Hematoxylin and eosin staining of the specimens obtained by liver biopsy revealed periportal and sinusoidal lymphohistiocytic infiltrates with intracellular debris $(\times 400)$.

lesions can be seen in the thickened mucosa in the rest of colon (Figure 4C).

Surgery was suggested after consultation of surgeons in view of the failed medical expectant treatment of alimentary tract hemorrhage. The preoperative diagnosis was Crohn's disease, alimentary tract hemorrhage, anemia, hypoproteinemia, hepatophyma, hydrothorax, seroperitoneum, electrolyte disturbances (hyponatremia, hypokalemia, hypochloremia), hemorrhagic shock, and cholecystitis. Emergency laparotomy was performed and intraoperative exploration had found that the liver was pervasive with diffused gray white nodules with hard texture, no wave motion, and compacted with neighboring tissues (the biggest one was approximately $3 \mathrm{~cm} \times 2 \mathrm{~cm}$ $\times 2 \mathrm{~cm}$ ); an apparent full dilatation of the colon with mass kermesinus blood, hyperemia, and edema in terminal ileum and colon and adhesion of cecum, lateral abdominal wall, and omentum majus; there was a $6 \mathrm{~cm} \times 6 \mathrm{~cm} \times 2 \mathrm{~cm}$ stiff ulcer with gray white color and hard texture that penetrated to placenta percreta in the ascending colon near the ileocecal valve. Lymphadenectasis can be seen in paracolic lymph nodes and mesentericae (Figure 4D). The intraoperative diagnosis was colon ulcer with hemorrhage and diffused occupying lesion in liver. Eventually, right hemicolectomy and liver-occupying lesion biopsy were executed.
Histologic examination demonstrated a dense and monomorphic small- to medium-sized lymphocytic infiltration in the mucosa and submucosa (Figure 5A). The immunohistochemical staining of the biopsy revealed scattered atypical large cells that were $\mathrm{CD} 3, \mathrm{CD} 7$, and $\mathrm{CD} 30$ positive and CD4, CD5, CD8, and CD56 negative (Figure 5B and C shows that CD3- and CD30-positive lymphoma cells are diffusely distributed). Liver sections revealed periportal and sinusoidal lymphohistiocytic infiltrates with intracellular debris (Figure 5D). Therefore, the final diagnosis was a type I EATL of the colon with liver metastasis. Unfortunately, the patient underwent steady deterioration and passed away due to disseminated intravascular coagulation and multiple organ failure 3 days after surgery.

The study was reviewed and approved by the Institutional Review Board of Lanzhou General Hospital of Lanzhou Military Command according to the standards of the Declaration of Helsinki.

\section{Discussion}

$\mathrm{CD}$ is a common disorder affecting $\sim 1 \%$ of population in several developed countries. ${ }^{6,7}$ EATL is the most common malignancy associated with $\mathrm{CD}$. The association between $\mathrm{CD}$ and lymphoma was first described by Fairley and 
Mackie. ${ }^{8}$ Then, in $1980 \mathrm{~s}$, Isaacson et $\mathrm{l}^{9,10}$ characterized these lymphomas as T-cell in origin. Followed by O'Farrelly et $\mathrm{al}^{11}$ described lymphoma cells adjacent to atrophic intestinal villi and coined the term EATL in 1986 . In 2\%-3\% of CD, malignant transformation occurred from a refractory state with intraepithelial lymphocyte aberration to ulcerative jejunitis before developing into EATL type I. ${ }^{12}$ The time period between diagnosis of CD and onset of EATL varied from few months to several decades.

Weight loss, abdominal pain, change in bowel habits, vomiting, diarrhea, gastrointestinal bleed, or an acute abdomen due to ulceration, obstruction, or perforation are the most common presentations of EATL. ${ }^{13}$ Physical signs include fever, lymphadenopathy, skin rash, hepatomegaly, and a palpable abdominal mass. ${ }^{14}$ EATL commonly arises in jejunum or ileum and usually is multifocal with ulcerative lesions. In early stage, EATL is localized in gastrointestinal tract or mesenteric lymph node. As the disease progresses, it can spread to liver, spleen, skin, or other organs.

Early diagnosis of EATL may offer a possibility of cure but remains challenging. The diagnosis of EATL was predominantly made at laparotomy, and most patients underwent an emergency procedure. ${ }^{15-17}$ In the current case, the diagnosis was initially regarded as Crohn's disease according to colonoscopy finding and pathological examination. After admission, both CT and magnetic resonance imaging found liver abnormality that was regarded as inflammatory bowel disease complicated with liver abscess; we thought it was the reason for fever, but the treatment with anti-infection, anti-inflammatory drug therapy failed. Finally, the postoperative pathological examination resulted in the diagnosis of EATL with liver metastasis due to lower gastrointestinal bleeding and emergency operation. The liver abscess is a misdiagnosis; it is proved to be a metastasis from the colon. Thus, it is clear that the clinical differential diagnosis is rather difficult between EATL and Crohn's disease. Histopathology is essential for confirming the diagnosis. Other symptoms include abdominal pain, weight loss, malabsorption, and protein-losing enteropathy, all of which are similar to CD, making the distinction between patients with and without EATL very difficult. ${ }^{18}$

There is no validated and standardized treatment guideline for EATL, and overall reported results with varied modalities are unsatisfactory. The treatment options are chemotherapy with or without radiotherapy and surgery. The surgery has poor outcomes, and its role is limited to debulking or treating complications such as perforation and obstruction. Chemotherapy seems to be more beneficial rather than surgery; however, rapid progression of disease during primary treatment, nutritional deficiency, performance status impairment, and treatment-related complications may prevent the use of adequate chemotherapy and radiotherapy in most patients with EATL. The clinical course of EATL is very aggressive; limited studies have reported a dismal 5 -year survival of $<20 \%{ }^{19,20}$ It has also been suggested that CD30 expression indicates a worse prognosis, and the present results reiterate the dismal outlook of patients with CD30-positive EATL. ${ }^{21}$ Recently, few case reports and small series have reported promising results in patients undergoing high-dose chemotherapy with autologous stem cell transplantation. ${ }^{15,16,22-27}$ Alemtuzumab, humanized antiCD52 monoclonal antibody currently used in the treatment of chronic lymphocytic leukemia or T-cell lymphoma, can be another option for EATL. ${ }^{28,29}$ Although an improved survival has been reported after aggressive consolidation therapy, the true efficacy of those treatment modalities remains to be determined.

The current case is unique in that the patient was at a very young age compared with previously reported cases (median age of diagnosis is 60 years). We suggest that EATL should be regarded as part of differential diagnosis in any patient presenting with abdominal pain, diarrhea, weight loss, and malabsorption because delay in treatment can result in irreversible clinical outcome.

\section{Acknowledgments}

Patient consent was obtained from the relatives of the patient. We are grateful to Dr Qin-Jun $\mathrm{Su}$, who is a pathologist in the Department of Pathology for providing the pathological pictures. The present study has been supported by the National Natural Science Foundation of China (81500454; 81401041) and the Medical Research Fund of Lanzhou Military Command (CLZ15JA02).

\section{Disclosure}

The authors report no conflicts of interest in this work.

\section{References}

1. Catassi C, Bearzi I, Holmes GK. Association of coeliac disease and intestinal lymphomas and other cancers. Gastroenterology. 2005; 128(4 suppl 1):S79-S86.

2. Brousse N, Meijer JW. Malignant complications of coeliac disease. Best Pract Res Clin Gastroenterol. 2005;19(3):401-412.

3. Verbeek WH, Van De Water JM, Al-Toma A, Oudejans JJ, Mulder CJ, Coupé VM. Incidence of enteropathy-associated T-cell lymphoma: a nation-wide study of a population-based registry in The Netherlands. Scand J Gastroenterol. 2008;43(11):1322-1328.

4. V G, Kudva R, Amprayil AJ. Enteropathy associated T cell lymphoma -a case report of an uncommon extranodal T cell lymphoma. J Clin Diagn Res. 2014;8(10):FD10-FD12. 
5. Pun AH, Kasmeridis H, Rieger N, Loganathan A. Enteropathy associated T-cell lymphoma presenting with multiple episodes of small bowel haemorrhage and perforation. J Surg Case Rep. 2014;2014(3):rju013.

6. Green PH, Cellier C. Celiac disease. N Engl J Med. 2007;357(17): 1731-1743.

7. Cellier C, Delabesse E, Helmer C, et al. Refractory sprue, coeliac disease, and enteropathy-associated T-cell lymphoma. French Coeliac Disease Study Group. Lancet. 2000;356(9225):203-208.

8. Fairley NH, Mackie FP. Clinical and biochemical syndrome in lymphadenoma. Br Med J. 1937;1(3972):375-404.

9. Isaacson PG. Coeliac disease and malignancy. Lancet. 1983;1(8330): 938.

10. Isaacson PG, O'Connor NT, Spencer J, et al. Malignant histiocytosis of the intestine: a T-cell lymphoma. Lancet. 1985;2(8457):688-691.

11. O'Farrelly C, O'Briain DS, Stevens F, Connolly CE, McCarthy C, Weir DG. Humoral response to wheat protein in patients with coeliac disease and enteropathy associated T cell lymphoma. Br Med J (Clin Res Ed). 1986;293(6552):908-910.

12. Al-Toma A, Verbeek WH, Hadithi M, von Blomberg BM, Mulder CJ. Survival in refractory coeliac disease and enteropathy-associated T-cell lymphoma: retrospective evaluation of single-centre experience. Gut. 2007;56(10):1373-1378.

13. Bagdi E, Diss TC, Munson P, Isaacson PG. Mucosal intra-epithelial lymphocytes in enteropathy-associated T-cell lymphoma, ulcerative jejunitis, and refractory coeliac disease constitute a neoplastic population. Blood. 1999;94(1):260-264.

14. Yanai S, Matsumoto T, Nakamura S, et al. Endoscopic findings of enteropathy-type T-cell lymphoma. Endoscopy. 2007;39(suppl 1): E339-E340.

15. Sieniawski M, Angamuthu N, Boyd K, et al. Evaluation of enteropathyassociated T-cell lymphoma comparing standard therapies with a novel regimen including autologous stem cell transplantation. Blood. 2010; 115(18):3664-3670.

16. Sieniawski MK, Lennard AL. Enteropathy-associated T-cell lymphoma: epidemiology, clinical features, and current treatment strategies. Curr Hematol Malig Rep. 2011;6(4):231-240.

17. Gale J, Simmonds PD, Mead GM, Sweetenham JW, Wright DH. Enteropathy-type intestinal T-cell lymphoma: clinical features and treatment of 31 patients in a single center. J Clin Oncol. 2000;18(4): $795-803$.
18. Ferreri AJ, Zinzani PL, Govi S, Pileri SA. Enteropathy-associated T-cell lymphoma. Crit Rev Oncol Hematol. 2011;79(1):84-90.

19. Delabie J, Holte H, Vose JM, et al. Enteropathy-associated T-cell lymphoma: clinical and histological findings from the international peripheral T-cell lymphoma project. Blood. 2011;118:148-155.

20. van de Water JM, Cillessen SA, Visser OJ, Verbeek WH, Meijer CJ, Mulder CJ. Enteropathy associated T-cell lymphoma and its precursor lesions. Best Pract Res Clin Gastroenterol. 2010;24(1):43-56.

21. Farstad IN, Johansen FE, Vlatkovic L, et al. Heterogeneity of intraepithelial lymphocytes in refractory sprue: potential implications of CD30 expression. Gut. 2002;51(3):372-378.

22. Al-Toma A, Mulder CJ. Review article: stem cell transplantation for the treatment of gastrointestinal diseases - current applications and future perspectives. Aliment Pharmacol Ther. 2007;26(suppl 2):77-89.

23. Ikebe T, Miyazaki Y, Abe Y, et al. Successful treatment of refractory enteropathy-associated T-cell lymphoma using high-dose chemotherapy and autologous stem cell transplantation. Intern Med. 2010; 49(19):2157-2161.

24. d'Amore F, Relander T, Lauritzsen GF, et al. Up-front autologous stem-cell transplantation in peripheral T-cell lymphoma: NLG-T-01. J Clin Oncol. 2012;30(25):3093-3099.

25. Jantunen E, Boumendil A, Finel H, et al; Lymphoma Working Party of the EBMT. Autologous stem cell transplantation for enteropathyassociated T-cell lymphoma: a retrospective study by the EBMT. Blood. 2013;121(13):2529-2532.

26. Vose J, Armitage J, Weisenburger D, et al; International T-Cell Lymphoma Project. International peripheral T-cell and natural killer/T-cell lymphoma study: pathology findings and clinical outcomes. J Clin Oncol. 2008;26(25):4124-4130.

27. Nijeboer P, de Baaij LR, Visser O, et al. Treatment response in enteropathy associated T-cell lymphoma; survival in a large multicenter cohort. Am J Hematol. 2015;90(6):493-498.

28. Gallamini A, Zaja F, Patti C, et al. Alemtuzumab (Campath-1H) and CHOP chemotherapy as first-line treatment of peripheral T-cell lymphoma: results of a GITIL (Gruppo Italiano Terapie Innovative nei Linfomi) prospective multicenter trial. Blood. 2007;110(7): 2316-2323.

29. Soldini D, Mora O, Cavalli F, Zucca E, Mazzucchelli L. Efficacy of alemtuzumab and gemcitabine in a patient with enteropathy-type T-cell lymphoma. Br J Haematol. 2008;142(3):484-486.
OncoTargets and Therapy

\section{Publish your work in this journal}

OncoTargets and Therapy is an international, peer-reviewed, open access journal focusing on the pathological basis of all cancers, potential targets for therapy and treatment protocols employed to improve the management of cancer patients. The journal also focuses on the impact of management programs and new therapeutic agents and protocols on

\section{Dovepress}

patient perspectives such as quality of life, adherence and satisfaction The manuscript management system is completely online and includes a very quick and fair peer-review system, which is all easy to use. Visit http://www.dovepress.com/testimonials.php to read real quotes from published authors. 